 \\ UF | $\mid$ FLORIVRIDITA \\ IFAS Extension
}

\section{Grape Root Borer Pest Management in Florida Vineyards ${ }^{1}$}

\section{Scott W. Weihman and Oscar E. Liburd ${ }^{2}$ \\ Introduction}

Over 1,000 acres of grapes are planted in Florida and are used for fresh fruit, U-pick, jam, juice, and wine. Florida is the third highest wine consuming state in the nation, with $\$ 8,000,000$ in wine sales annually. There are 13 registered wineries in Florida, and with the increasing popularity of visiting vineyards for wine-tastings, many wineries have to import grape juice from other states and countries to keep up with the demand. In comparison with other crops, grapes are a relatively small crop in Florida, but have a strong potential for growth.

The primary grape grown in Florida is the muscadine (Vitis rotundifolia Michx.), which is native to the southeastern U.S. It is well adapted to Florida conditions, does not succumb to many diseases or pests, and is highly rated as a sustainable crop. The American bunch grape (Vitis labrusca L.) is also native to the southeastern U.S. It is very susceptible to Pierce's disease and other pathogens, so disease-resistant hybrids were developed (Euvitis spp.) which are now widely planted in Florida.

Euvitis is the second-most planted grape, and is used mostly for traditional wines. The European bunch grapes (Vitis vinifera), such as Pinot Noir and
Chardonnay, have not been successfully grown in Florida, due primarily to Pierces disease.

The most important insect pest of grapes in Florida is the grape root borer, Vitacea polistiformis (Harris), a sesiid moth. The grape root borer (GRB) is native to the eastern United States, and ranges south of a line from Vermont across to Minnesota and east of the Mississippi River states, and occurs throughout peninsular Florida. Grape root borer have been damaging vineyards in the southeastern U.S. for over 150 years. It has been declared the most destructive insect pest of grapes in many states including Georgia, North Carolina, and Florida.

\section{Description}

Grape root borer eggs are indented brown ovals, smaller than the head of a pin (Figure 1A). The larvae are creamy white, and eventually reach 1 1/2 inches long (Figure 1B). The pupal cases, which emerge from the cocoons, are one inch long, golden-brown, transparent cases (Figure 1C). The GRB adult is a clearwing moth with brown scales on the forewing, clear hind wings, and a brown abdomen with orange or yellow bands (Figure 1D). Its size, flight behavior, buzzing sound, and appearance resemble a paper wasp (Polistes spp.). Most moths are nocturnal, but

1. This document is Fact Sheet ENY-831, a series of the Entomology and Nematology Department, Florida Cooperative Extension Service, Institute of Food and Agricultural Sciences, University of Florida. Publication date: July 2005. Please visit the EDIS Website at http://edis.ifas.ufl.edu.

2. Scott W. Weihman, research associate, and Oscar E. Liburd, associate professor, Department of Entomology and Nematology, Cooperative Extension Service, Institute of Food and Agricultural Sciences, University of Florida, Gainesville, 32611. 
GRB fly during the day, similar to the wasps they imitate. The males are smaller than the heavier females with four orange tufts extending beyond the abdomen (Figure 2).

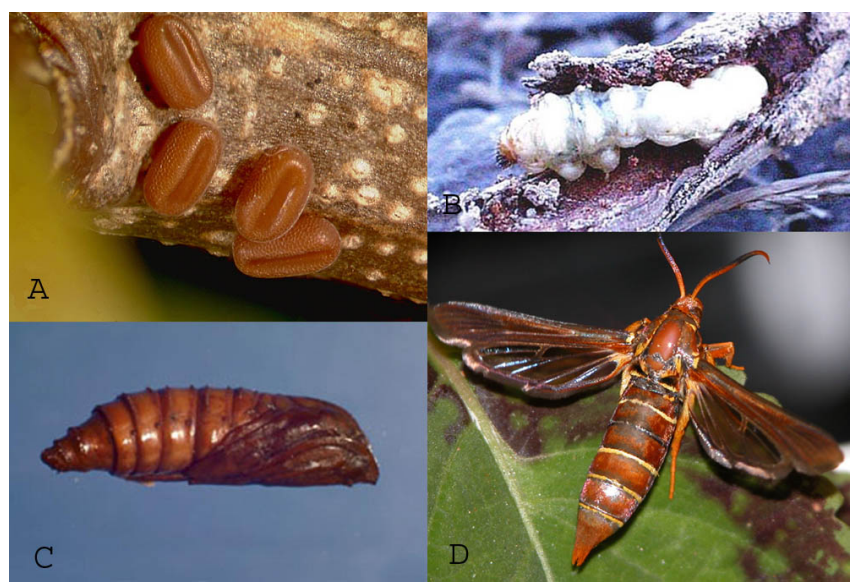

Figure 1. Life stages: egg (A), larval stage (B), pupal stage (C), and adult (D). Credits: A and D (Scott Weihman, University of Florida), B (Peacock), C (James Soloman, USDA Forest Service)

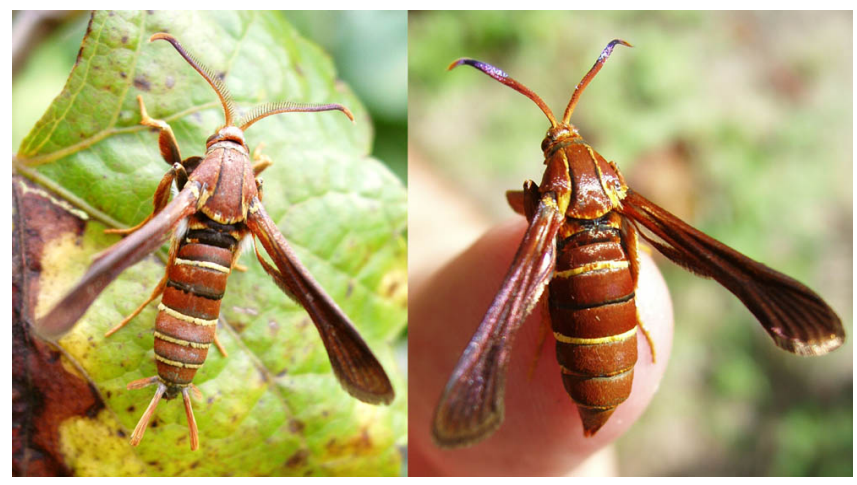

Figure 2. Grape root borer male (left) and female (right).

\section{Life Cycle}

As with other moths, the GRB has four life stages (Figure 2): egg, larval stage, a pupal stage (cocoon), and adult. Eggs are laid on vine trunks, branches, and weeds at the base of vines. After about 18 days, the larva emerges and begins burrowing into the soil in search of a grape root. It enters the root and begins feeding, moving in the direction of the crown. After the larva is fully mature, it leaves the root and burrows up to $5 \mathrm{~cm}$ below the soil surface to form its cocoon, within which the adult moth develops (Figure 3). After 30-45 days, the adult will emerge from the cocoon and make its way to the soil surface, still partly enclosed in a pupal case. As it reaches the soil surface, the adult leaves the pupal case (Figure 3) and usually crawls onto the grape trunk or weeds to dry and recover. Shortly thereafter, female GRB will begin to emit their pheromone to attract the males in order to mate. After mating the female will begin to lay her eggs (roughly 350 ) and the cycle repeats. Adult GRB live for roughly 7 days. They do not feed during this time, their purpose being only to reproduce. Grape root borer can live between 1-3 years, depending on latitude, but probably have a mostly one-year life cycle in Florida.

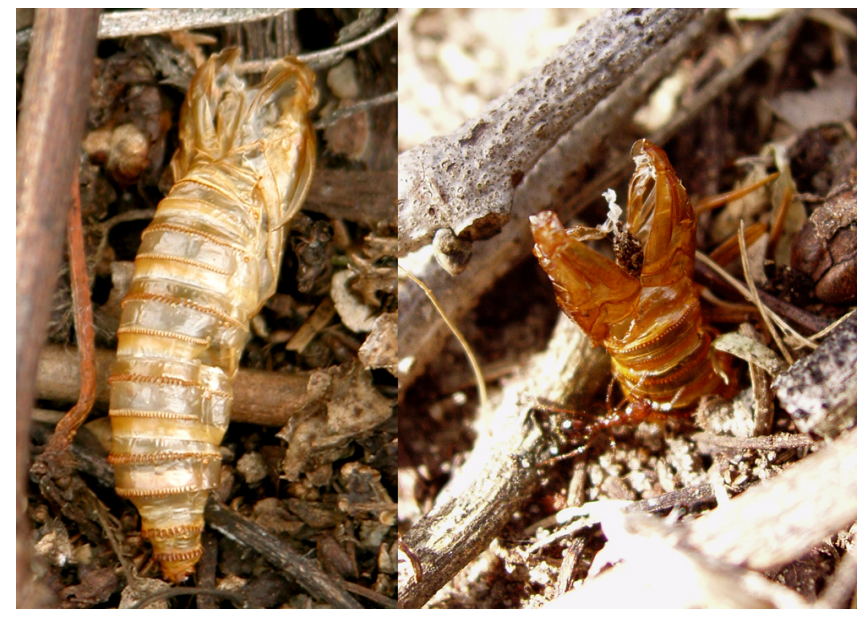

Figure 3. Empty pupal cases of recently emerged adult grape root borer.

The adults can emerge over a six-month period in Florida, compared with 2-3 months in northern states. The adults begin emerging from their cocoons in early summer and continue emerging until the weather begins to cool, sometime in the fall. Flight activity peaks during the time of muscadine grape harvest in Florida (Figure 4).

\section{Damage}

Serious infestations can cause loss of vigor in grapes, decreases in yields, and high vine mortality. Entire vineyards have been destroyed in Missouri, Arkansas, Virginia, South Carolina, and Florida. The grape root borer is often overlooked or ignored by Florida grape farmers. The damaging life stage (larval stage) of the GRB occurs underground, and the adult goes unnoticed because of its resemblance to the common paper wasp. Farmers often attribute reduced yields to weather conditions or pathogens. The exposed roots of infested vines have tunnels filled with reddish sawdust-like excrement and trunk girdling. Damage to a vine may not be apparent for 


\section{Grape Root Borer Emergence Patterns for 10 Florida Counties}

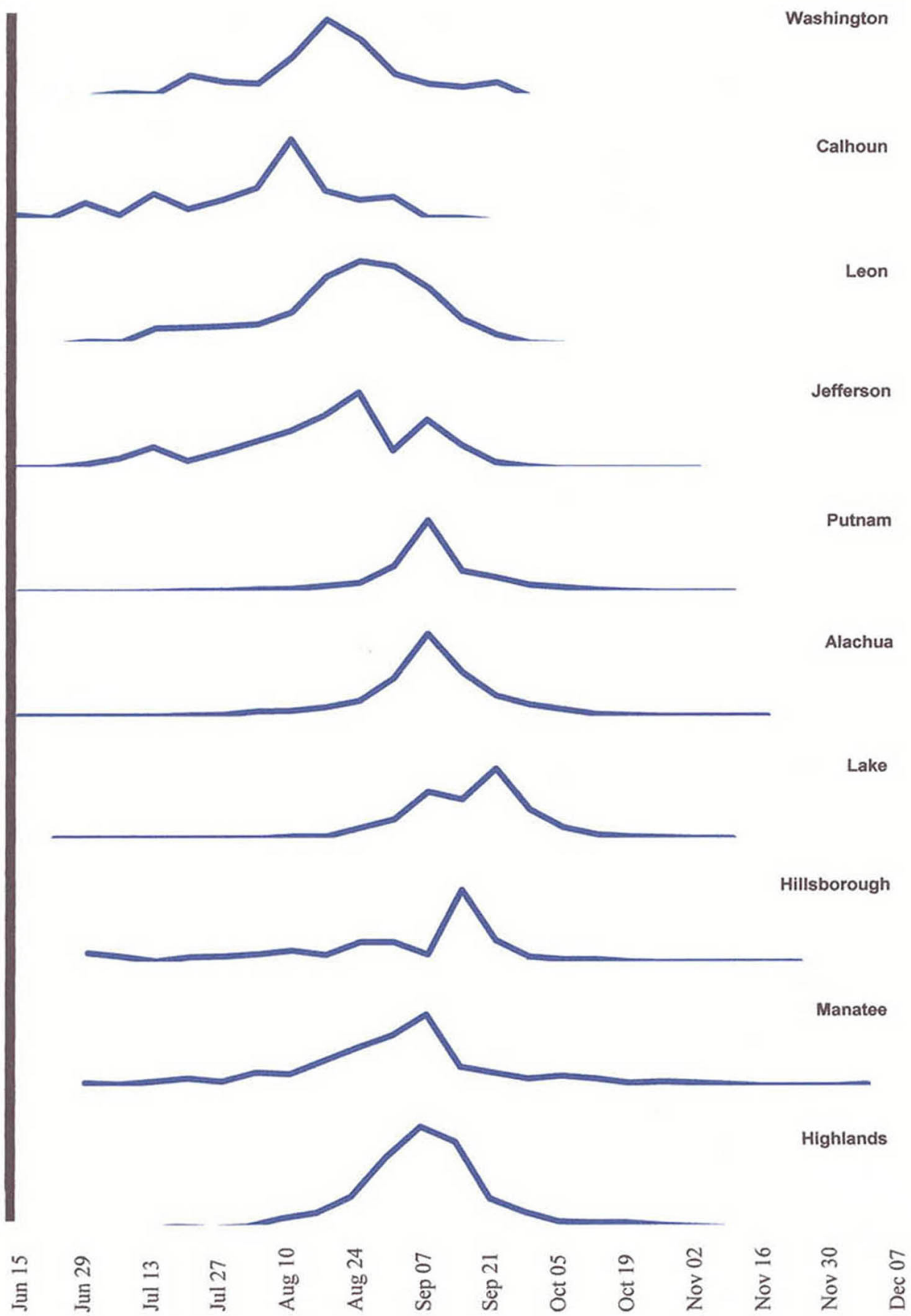

Figure 4. Grape root borere seasonal distribution curves for 10 Florida counties in 2003 indicating beginning of emergence in early summer, end of season, and peak times of emergence.

several years, and extensive damage may be done before symptoms appear. Symptoms include yellowing of leaves, smaller leaves and berries, reduced shoot growth, dieback of portions of the vine, and reduced yields. These symptoms occur gradually. It is difficult to diagnose GRB infestation from these symptoms since they also occur as the result of pathogens and other problems. The traditional method of detecting GRB activity, besides digging up the vines and inspecting for larvae, is to 
count the pupal casings under the vines (Figure 3). The majority of these will occur within a one-foot radius of the trunk.

\section{Monitoring}

It is important to monitor the GRB populations in vineyards in order to be aware of infestation levels. In our studies, we found GRB in all of the 19 vineyards we monitored. They invade vineyards from native wild grapes, which are pervasive throughout the state. As already discussed, one way to monitor GRB is to count the pupal casings (Figure 4) found at the base of vines. An economic injury level (EIL) that was established in the 1980s indicates that 29 pupal cases per acre were sufficient to cause economic damage. This EIL was set in Georgia and may not be accurate for Florida, with its longer GRB flight season.

For Florida, it may be more advisable (and less time-consuming) to monitor GRB populations with pheromone-baited bucket traps (Figure 5). A lure is placed in the central cage of the trap (Figure 5) which contains a synthetic version of the female GRB pheromone. A pesticide strip (Hercon vaportape) is attached to the inner bucket. This is how it works: the male is lured to the trap, lands on the slippery surface and then slides into the inner bucket and is subsequently killed by the pesticide.

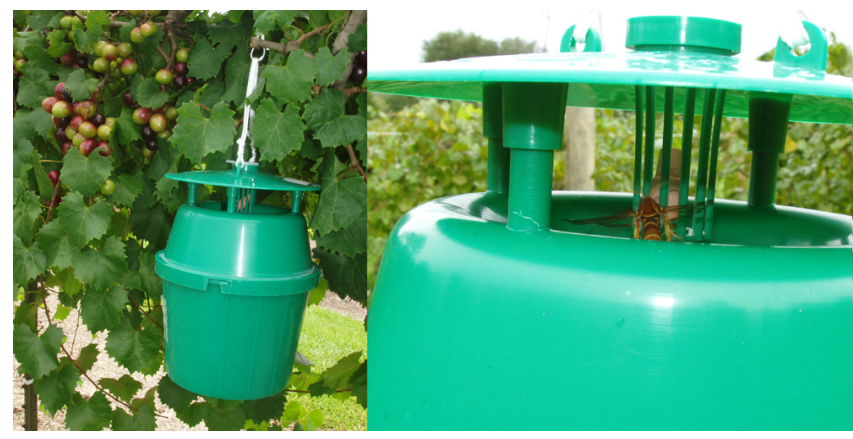

Figure 5. Universal Moth Trap (bucket trap) hung on the trellis wire and baited with the GRB pheromone (right). GRB male attracted to the pheromone lure in a cage at the center of the trap.

This trap will catch only males. As of this printing, no economic injury levels have been set for monitoring with bucket traps. They can, however, give you an indication of the severity of infestation, and whether growers need to implement control measures. One to two traps per acre may be sufficient for monitoring purposes. Traps, vaportapes, and GRB pheromones can be obtained from Great Lakes IPM (www.greatlakesipm.com or 1-800-235-0285).

\section{Management}

Many strategies for GRB control have been investigated, including mounding, covering the base of vines with ground cloth, and chemical control with Lorsban 4E®. Mounding is a technique by which a layer of soil is ridged over the base of the grape plant and under the trellis to prevent the adults from emerging. Mounding has been an effective control in other states, but is probably not practical in Florida. It would likely have to be done several times a season, resulting in heavy root disturbance.

Applying ground cloth under the base of vines is another strategy used to prevent GRB from emerging from the soil, as well as entering the root zone.

However, it is initially expensive and time-consuming to install, and the cloth is vulnerable to damage from machines and workers.

The conventional method of GRB control involves the use of Lorsban $\mathbf{4 E}$ (chlorpyrifos). Lorsban can only be used once per season and 35 days pre-harvest, which is well before the peak emergence period, and after harvest. Since GRB emerge over a long period in Florida, and Lorsban is effective for roughly four weeks, it cannot effectively control the majority of the GRB population (Figure 6). For best control of GRB by Lorsban, it should be applied post-harvest for both muscadine and bunch grape-growers (Figure 6). However, vineyards that harvest over extended periods of time, such as U-pick and fresh fruit operations, may find better results applying Lorsban pre-harvest.

There is a new formulation of chlorpyrifos, Lorsban WG (water dispersible granule). This is a safer formulation to apply, with reduced odor, and may have a greater residual effect. The harvest intervals are the same, which can be problematic for growers with high populations of GRB. Lorsban 4E is not available to the hobbiest, or the unlicensed farmer. However, Lorsban WG is available to licensed farmers. For these chemicals to be effective, 


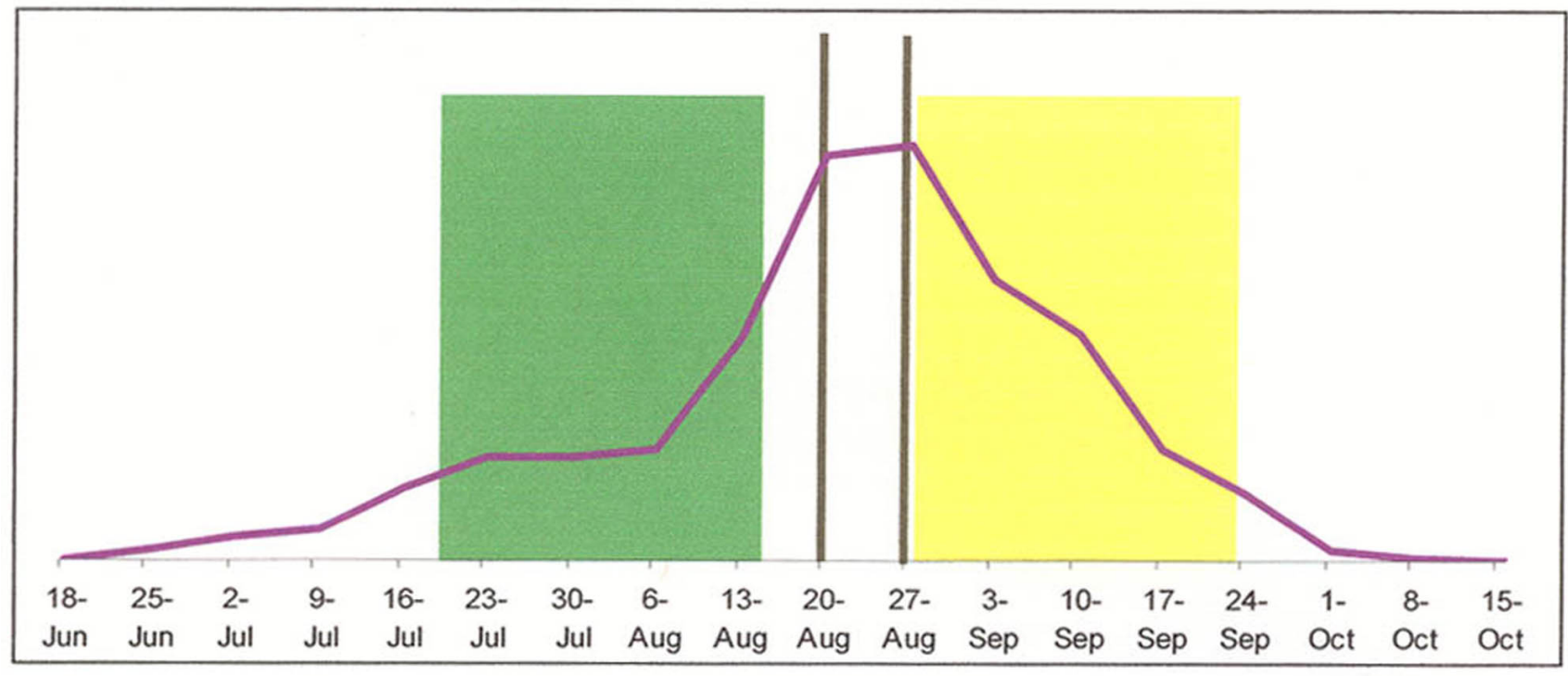

Figure 6. Timing of Lorsban in muscadine grapes. Grape root borer emergence curve for the Panhandle region (purple), with vertical bars representing period of grape harvest. Green box indicates 35 days pre-harvest application and its period of effect. Yellow box represents post-harvest application in which more GRB can potentially be destroyed.

weeds and debris must be removed from the surface area prior to application.

\section{Mating Disruption}

Mating disruption is a tactic that uses the female insects pheromones to confuse males and prevent them from finding mates. In nature, when a female moth is ready to mate, she releases her pheromone into the air, and a male follows the scent until he encounters her. Under mating disruption, dispensers with a synthetic female pheromone (usually in the form of twist-ties, Figure 7) are placed throughout the crop. The air becomes inundated with pheromone and the male is unable to track the scent to a female. Mating, then, does not occur, affecting the next generation.

For our study, we used leopard moth pheromone twist-ties, because GRB twist-ties are not being produced. We placed 254 twist-ties (Figure 7) per acre, which is approximately 1 twist-tie per vine, depending on the number of vines per acre. They were hung on the trellis wire or branches near the wire. Twist-ties should be loosely fastened so that they won't girdle the vines as they grow. They are applied once per season at the beginning of the GRB flight season (see Figure 4) and removed at the end of the season or during pruning. We placed two

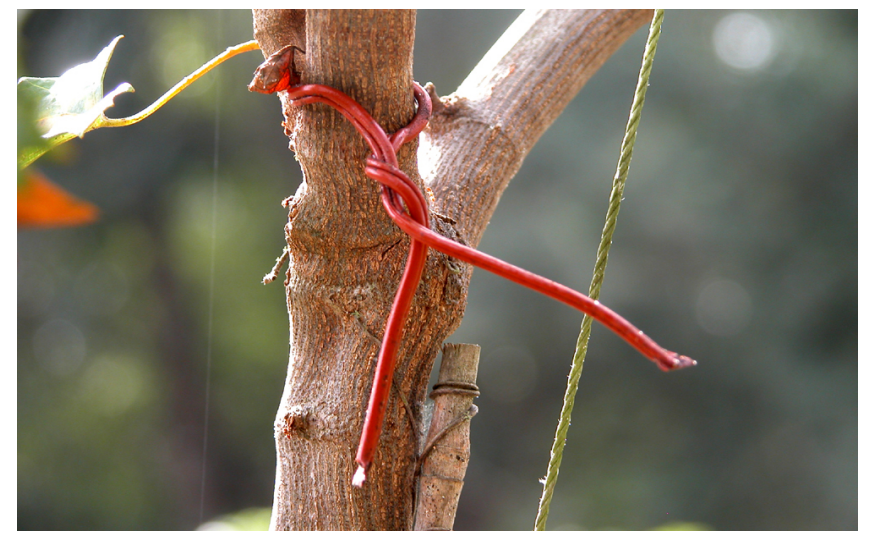

Figure 7. Pheromone twist-tie applied to grape branch.

monitoring traps with the GRB pheromone in each plot to monitor the success of the treatment.

The success of our experiment was determined by "trap shutdown." The traps in the treated plot serve as surrogate females. If male GRB are able to locate the trap, then they must also be able to find true females. So if large numbers of GRB males are caught in the traps, this indicates that the twist-ties are not working to disrupt mating; in turn, if small numbers are found compared to an untreated section, then the treatment is working (trap shutdown).

In our study, no male GRB were found in any of the traps in the pheromone twist-tie plots at any of the farms studied (Figure 8). This strongly suggests that the males were unable to find the females and mate. 


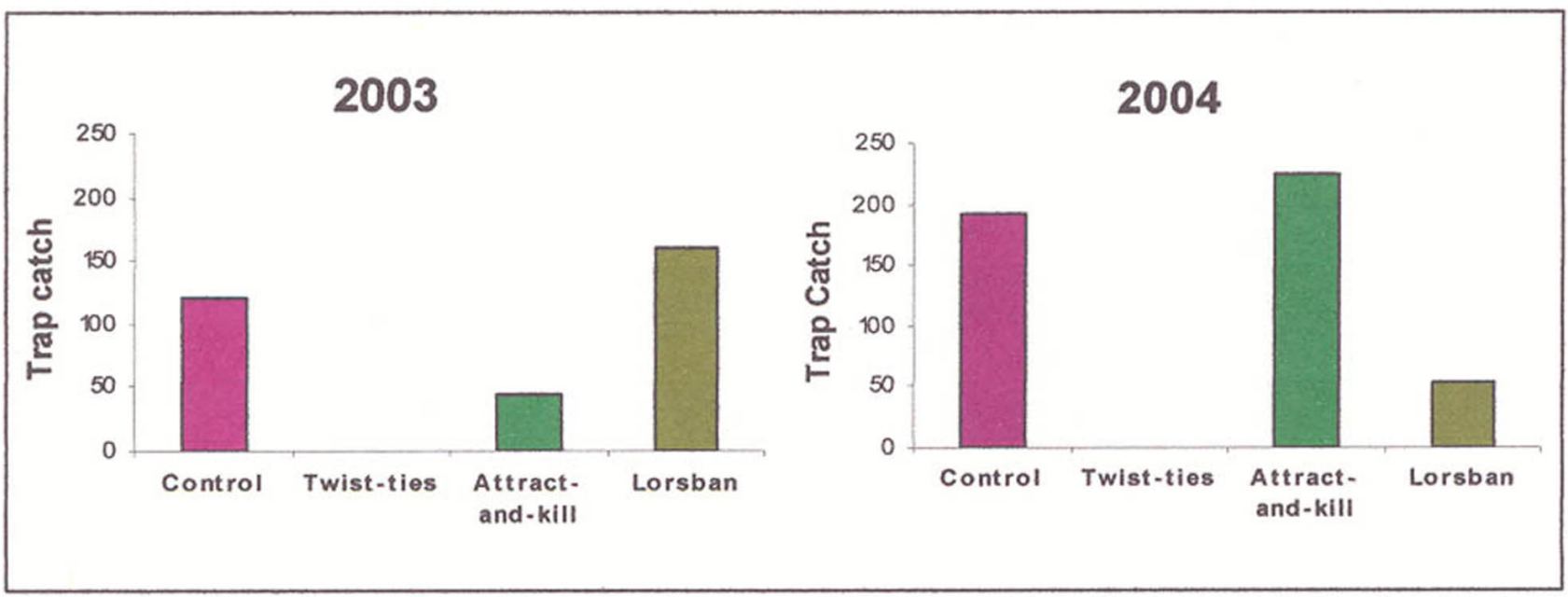

Figure 8. Results of pheromone experiment for 2003 and 2004. Bars represent number of grape root borer males captured in each of four treatments: untreated control, pheromone twist-ties, attract-and-kill, and Lorsban. Shorter bars or no bars indicate mating disruption success.

As of this writing, the cost of the twist-ties is $\$ 116$ per acre. In our experiment we used 254 twist-ties per acre. This number may be high. Traditionally, 100 twist-ties per acre is the number that has been used. In order to bring the price down, we will be investigating different rates of application to find the smallest number of twist-ties that will still effectively disrupt mating.

The leopard moth twist-ties are not currently being sold in the United States. The product is called Isonet- $Z$ and is produced by the Shin-Etsu Chemical Co. of Japan. It is sold in Italy by CBC-Europe (www.cbc-europe.it/biocontrol/). With continuing research success with this product, and an indication of grower interest, we may be able to market this product in the U.S. through a pest management retail outlet.

\section{Attract-and-Kill}

Attract-and-kill (A\&K) is a promising new technology that involves an attractant, such as a pheromone, and a toxicant. Unlike mating disruption, which functions by confusing the insect, attract-and-kill technology attracts the insect with its own pheromone to a poison source in the form of a pesticide laden gel drop (Figure 9a). The male is poisoned and dies, usually before mating with a female. The theory is that males will encounter a drop (900 drops per acre) more often than a female GRB. Fewer eggs are produced, and the next generation is smaller. The attracticide droplets contain smaller amounts of pheromone than the twist-ties so that they can attract male moths rather than cause mating disruption. It has been successfully used on several moth species including codling moth. One of the benefits of using this technique is that it targets the desired insect pests and has little effect on beneficial insects. Also, there is no spray drift with attract-and-kill systems and no pesticide residues are left on the fruit. It is easy to apply and lesser amounts of pesticides will be used per acre (4.05 grams/ acre) than a traditional chemical treatment.

Recently, IPM Tech (Portland, OR) developed an attracticide for grape root borer, called Last Call ${ }^{\mathrm{TM}}$ GRB. This had not previously been tested under field conditions. It comes in a calibrated hand pump (Figure 9b) that releases the same-sized drop with each squeeze. The directions call for 900 drops per acre, which is roughly equivalent to 2-4 drops per vine depending on vine spacing. Drops are applied to the trunks of the vines 3-5 ft. above the ground. The first application is at the start of the GRB emergence period (Figure 4), and is reapplied every 6 weeks thereafter.

The results of our A\&K experiment are shown in Figure 8. In 2003, fewer GRB were trapped in the A\&K sections than in the untreated control and Lorsban sections suggesting that the males were being killed by the pesticide. A\&K shows potential for control of GRB. However, in Florida's harsh 
summer climate, the drops may deteriorate more quickly than in other areas of the U.S., requiring it to be reapplied more frequently.

LastCall-GRB costs $\$ 100$ per acre and it requires roughly one hour to treat an acre and 3-4 applications per season. Depending on the size of the vineyard, this could be rather labor-intensive. Future studies will evaluate how many drops per acre would provide effective control. Instead of 900 drops per acre, perhaps the drops $(1 \mathrm{drop}=0.05 \mathrm{~g})$ could be consolidated into larger amounts and applied on fewer vines. For example, $1.5 \mathrm{~g}$ drops could be applied to 30 vines $(=45 \mathrm{~g}$ of $\mathrm{A} \& \mathrm{~K})$.

As of this writing, Last Call ${ }^{\mathrm{TM}}$ GRB is still in the experimental stage, and is not available commercially.

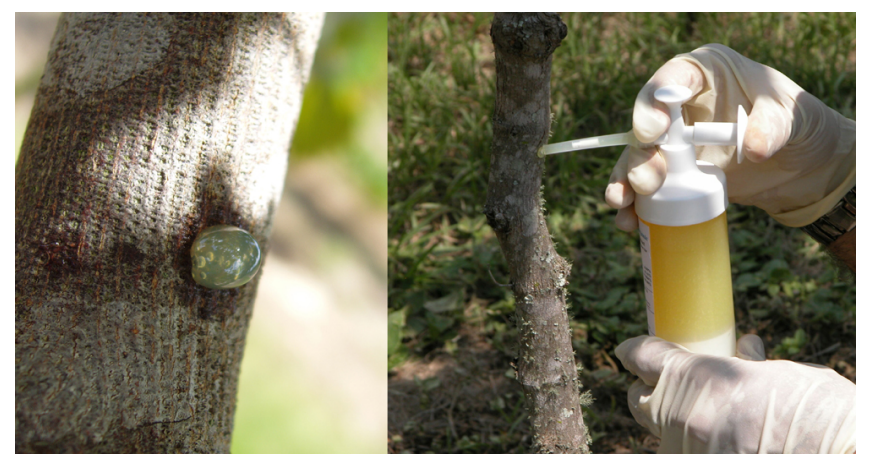

Figure 9. a) Attract-and-kill gel drop applied to grape trunk. b) Calibrated hand pump for Last Call ${ }^{\mathrm{TM}}$ GRB.

\section{Conclusion}

Due to its hidden nature and short adult life span, the grape root borer is a difficult pest to control. No one tactic will be sufficient in controlling GRB. Wild grapes occur quite extensively in Florida, and GRB will always be immigrating into vineyards from forested areas. An integrated pest management program is necessary to control GRB in Florida vineyards. This includes good weed management. It is especially important to keep the area at the base of vines and under the trellis weed-free. Weeds provide substrate upon which to lay eggs, and are the preferred mating sites for the adults (Sarai, 1972). They also provide cover to the newly emerged adults and create a humid environment and protection from predators for newly emerged larvae. Another important tactic is reduction of chemical usage, as well as the adoption of reduced-risk pesticides. The overuse of broad-spectrum pesticides kills off many of the beneficial insects that help control pest species. This often allows pest insects to build up to even higher populations. Pesticides should not be used by fixed schedules, but only under pest outbreak conditions. Farmers need to monitor GRB populations and implement control strategies when the population is high. These strategies may include the use of Last Call-GRB (A\&K), Lorsban, and the use of pheromone twist-ties for mating disruption.

\section{References}

All, J.N., J.D. Dutcher, and M.C. Saunders. 1987. Control program for the grape root borer in grape vineyards of the eastern United States. Down to Earth 43(2), Aug:10-12.

All, J.N., D.L. Horton and J.D. Dutcher. 1989. A pest management program for the grape root borer using Lorsban. Proc. Vit. Sci. Sym. Florida A\&M University (Tallahassee, FL): 60-61.

Johnson, D.T, B.A. Lewis, and J.W. Snow. 1991. Control of grape root borer (Lepidoptera: Sesiidae) by mating disruption with two synthetic sex pheromone compounds. Environ. Entomol. 20:931-934..

Pearson, G.A. and J.R. Meyer. 1996. Female grape root borer (Lepidoptera: Sesiidae) mating success under synthetic sesiid sex pheromone treatment. J. Entomol. Sci. 31:323-330.

Webb, S.E. 1991. Management of grape root borer in Florida with a pheromone. Proc. Fla. State Hort. Soc. 104:3-5.

Webb, S.E., R.K. Sprenkel, and J.L. Sharp. 1992. Seasonal flight activity of grape root borer (Lepidoptera:Sesiidae) in Florida. J. Econ. Entomol. 85:2161-2169.

Weihman, Scott. 2005. Monitoring and control tactics for grape root borer Vitacea polistiformis Harris (Lepidoptera: Sesiidae) in Florida Vineyards. [MS Thesis]. University of Florida, Gainesville, FL. 